\title{
Minimally invasive surgery for Achilles tendon pathologies
}

This article was published in the following Dove Press journal:

Open Access Journal of Sports Medicine

2 July 2010

Number of times this article has been viewed

\author{
Nicola Maffulli' \\ Umile Giuseppe Longo \\ Filippo Spiezia ${ }^{2}$ \\ Vincenzo Denaro ${ }^{2}$ \\ 'Centre for Sports and Exercise \\ Medicine, Barts and The London \\ School of Medicine and Dentistry, \\ London, England; 'Department of \\ Orthopedic and Trauma Surgery, \\ Campus Bio-Medico University, \\ Rome, Italy
}

\begin{abstract}
Minimally invasive trauma and orthopedic surgery is increasingly common, though technically demanding. Its use for pathologies of the Achilles tendon (AT) hold the promise to allow faster recovery times, shorter hospital stays, and improved functional outcomes when compared to traditional open procedures, which can lead to difficulty with wound healing because of the tenuous blood supply and increased chance of wound breakdown and infection. We present the recent advances in the field of minimally invasive AT surgery for tendinopathy, acute ruptures, chronic tears, and chronic avulsions of the AT. In our hands, minimally invasive surgery has provided similar results to those obtained with open surgery, with decreased perioperative morbidity, decreased duration of hospital stay, and reduced costs. So far, the studies on minimally invasive orthopedic techniques are of moderate scientific quality with short follow-up periods. Multicenter studies with longer follow-up are needed to justify the long-term advantages of these techniques over traditional ones.
\end{abstract}

Keywords: tendinopathy, rupture, percutanous repair, less invasive

\section{Introduction}

Minimally invasive trauma and orthopedic surgery is increasingly taking hold. ${ }^{1-15}$ It is technically demanding. Although some would consider that arthroscopy is the ultimate minimally invasive procedure, over the course of the last few years many techniques and philosophies of treatment have been introduced and have since evolved. Now such techniques are used to manage fractures, nonunions, malunions, bone infections, arthritis, and deformities. ${ }^{1-15}$ These techniques have the theoretic advantage of decreasing recovery and rehabilitation times because surgical exposure and deep tissue dissection are smaller and gentler to the soft tissues. ${ }^{1-15}$

Traditional open surgical approaches for the management both of tendinopathy and ruptures of the Achilles tendon (AT) have resulted in high risk of infection and morbidity. ${ }^{16}$ For this reason, minimally invasive surgical approaches have been developed ${ }^{5,17-20}$ with the aim of obtaining faster recovery times, shorter hospital stays, and improved functional outcomes. ${ }^{5,17-19}$ Open procedures on the AT can lead to difficulty with wound healing because of the tenuous blood supply and increased chance of wound breakdown and infection. ${ }^{16}$ Moreover, the broad exposure given by open procedures may cause extensive iatrogenic disruption of the subcutaneous tissues and paratenon, increasing the potential for peritendinous adhesions. Critics have raised questions about increased percentage of complications (eg, sural nerve damage). ${ }^{21,22}$

We present the recent advances in the field of minimally invasive AT surgery for tendinopathy, acute ruptures, chronic tears, and chronic avulsions of the AT. ${ }^{5,8,17-20}$ 


\section{Achilles tendinopathy management: evolving concepts}

The etiology of pain in Achilles tendinopathy is widely debated, with recent evidence that neovascularization and neoinnervation may be responsible. ${ }^{23-33}$ Neovascularization is often present in patients with tendinopathy, and the area in which patients perceive most pain correlates with the area where most neovascularization occurs on power Doppler ultrasound scan. ${ }^{27,34}$

Historically, the management of Achilles tendinopathy has focused on the area of tendinopathy within the tendon. ${ }^{35-37}$ The aim of surgery was to excise fibrotic adhesions and remove degenerated nodules. ${ }^{38}$ Other options included producing multiple longitudinal tenotomies along the long axis of the tendon to (1) detect intratendinous lesions, (2) restore vascularity, and (3) possibly stimulate the remaining viable cells to initiate cell matrix response and healing. ${ }^{39}$

In patients with isolated Achilles tendinopathy with no paratendinous involvement and a well-defined nodular lesion less than $2.5 \mathrm{~cm}$ long, multiple percutaneous longitudinal tenotomies can be used when conservative management has failed. ${ }^{19}$ An ultrasound scan may be helpful to accurately determine the precise location of tendinopathy. ${ }^{20}$

New surgical management options are directed to manage the neovascularization outside the tendon. ${ }^{5}$ To this aim, new minimally invasive stripping of the $\mathrm{AT}^{5,6,10}$ and endoscopy ${ }^{40,41}$ can be performed.

\section{Achilles tendinopathy Multiple percutaneous longitudinal tenotomies}

The patient lies prone on the operating table with the feet protruding beyond the edge, and the ankles resting on a padded sandbag. ${ }^{19}$ The tendon is accurately palpated, and the area of maximum swelling and/or tenderness is marked and checked again by ultrasound scanning. The skin and the subcutaneous tissues over the AT are infiltrated with 10 to $15 \mathrm{~mL}$ of plain $1 \%$ lignocaine.

A number 11 surgical scalpel blade (Swann-Morton Ltd, Sheffield, England) is inserted parallel to the long axis of the tendon fibers in the marked area(s) with the cutting edge pointing cranially. This initial stab incision is made in the central portion of the diseased tendon. With the blade held still, a full passive ankle dorsiflexion movement is produced. After the position of the blade is reversed, a full passive ankle plantarflexion movement is produced. A tenotomy is thereby produced over a length of up to approximately $3 \mathrm{~cm}$ using only a stab incision. The procedure is repeated $2 \mathrm{~cm}$ medial and proximally, medial and distally, lateral and proximally, and lateral and distally to the site of the first stab wound. The pattern of the five stab incisions is similar to the number five on a dice. The five wounds are closed with steristrips, dressed with cotton swabs, and several layers of cotton wool and a crepe bandage are applied.

\section{Ultrasound-guided percutaneous tenotomy}

The patient is positioned as described for the previous technique. A bloodless field is not necessary. The tendon is accurately palpated, and the area of maximum swelling and/or tenderness is marked and checked by ultrasound scanning..$^{20}$ The skin is prepped with an antiseptic solution, and a sterile longitudinal $7.5 \mathrm{MHz}$ ultrasound probe is used to confirm the area of tendinopathy. Before infiltration of the skin and subcutaneous tissues over the AT with $10 \mathrm{~mL}$ of $1 \%$ Carbocaine $^{\circledR}, 7 \mathrm{~mL}$ of $0.5 \%$ Carbocaine is used to infiltrate the space between the tendon and the paratenon. This brisement procedure attempts to free the paratenon from the tendon by disrupting adhesions between the two structures.

Under ultrasound guidance, a number 11 surgical scalpel blade (Swann-Morton Ltd) is inserted parallel to the long axis of the tendon fibers in the center of the area of tendinopathy, as assessed by high-resolution ultrasound imaging. The cutting edge of the blade points caudally and penetrates the whole thickness of the tendon. With the blade held still, a full passive ankle flexion is produced.

All subsequent tenotomies are performed through this same stab incision unless there is an extensive area of tendinopathy or an additional area of tendon disease. The scalpel blade is then retracted to the surface of the tendon, inclined 45 degrees on the sagittal axis, and the blade is inserted medially through the original tenotomy. With the blade held still, a full passive ankle flexion is produced. The whole procedure is then repeated with the blade inclined 45 degrees laterally to the original tenotomy and inserted laterally through the original tenotomy. Again with the blade kept still, a full passive ankle flexion is produced. The blade is then partially retracted to the posterior surface of the AT, reversed 180 degrees so that its cutting edge now points cranially, and the procedure is repeated, with care taken to dorsiflex the ankle passively. A steristrip (3M United Kingdom PLC, Berkshire, England) can be applied on the stab wound, or the stab wound can be left open. ${ }^{42,43}$ The wound is dressed with cotton swabs, and several layers of cotton wool and a crepe bandage are applied. 


\section{Minimally invasive stripping}

The patient undergoes local or general anesthesia, according to surgeon or patient preferences. The patient is positioned prone with a calf tourniquet which is inflated to $250 \mathrm{mmHg}$ after exsanguination. Skin preparation is performed in the usual fashion.

Four skin incisions are made. The first two incisions are $0.5 \mathrm{~cm}$ longitudinal incisions at the proximal origin of the AT, just medial and lateral to the origin of the tendon. The other two incisions are also $0.5 \mathrm{~cm}$ long and longitudinal, but $1 \mathrm{~cm}$ distal to the distal end of the tendon insertion on the calcaneus.

A mosquito clamp is inserted in the proximal incisions, and the AT is freed of the peritendinous adhesions. A Number 1 unmounted Ethibond (Ethicon, Somerville, NJ) suture thread is inserted proximally, passing through the two proximal incision, anterior to the AT at the border between the AT and the Kager's triangle. The Ethibond is retrieved from the distal incisions. Using a gentle see-saw motion, similar to using a Gigli saw, the Ethibond suture thread is made to slide posterior to the tendon, which is stripped and freed from the fat of Kager's triangle.

If necessary, using an 11 blade (Swann-Morton Ltd), longitudinal percutaneous tenotomies parallel to the tendon fibres are made. ${ }^{19,20,44}$

The subcutaneous and subcuticular tissues are closed in a routine fashion, and Mepore (Molnlycke Health Care, Gothenburg, Sweden) dressings are applied to the skin. A removable scotch cast support with Velcro straps can be applied if deemed necessary.

\section{Endoscopy}

Endoscopic procedure have been described for the management of tendinopathy. ${ }^{41,45-49}$ In the Van Dijk's technique, ${ }^{41}$ with the patient positioned prone, firstly a distal portal is established on the lateral border of the AT, $2 \mathrm{~cm}$ to $3 \mathrm{~cm}$ distal to the pathologic thickened nodule. A proximal portal is located $2 \mathrm{~cm}$ to $4 \mathrm{~cm}$ above the nodule on the medial border of the AT. These portals allow you to visualize and work around the whole surface of the AT over a length of approximately $10 \mathrm{~cm}$. After the skin incisions, a mosquito clamp is introduced, followed by the blunt $2.7 \mathrm{~mm}$ trocar in a craniolateral direction. Looking ventrally over the edge of the tendon on the craniolateral side, a $30^{\circ} 2.7 \mathrm{~mm}$ arthroscope is introduced. The AT is easily identified at the level of its healthy portion. To minimize the risk of iatrogenic damage to neurovascular structures, the arthroscope must be kept on the tendon. The cranial portal is made introducing a spinal needle, followed by a mosquito clamp and probe.
The plantaris tendon is identified just medial to the AT. In patients with paratendinopathy, the plantaris tendon, the AT, and the paratenon are tight together in the inflammatory process, and surgery aims to remove the local thickened inflamed paratenon and release of the plantaris tendon. A resection of the paratenon is performed on the anterior side of the tendon at the level of the painful nodule. At this level, it is possible to find neovascularization, which is accompanied by small nerve fibers. These neurovascular endings can be removed by blunt dissection with the trocar followed by removal of tissue with the full-radius $2.7 \mathrm{~mm}$ resector shaver. Changing portals can be helpful. At the end of the procedure, it must be possible to move the arthroscope over the complete symptomatic area of the AT.

Thermann et a $\mathrm{l}^{40}$ described a different technique of endoscopic debridement of the ventral neovascularized area, the peritenon, and the AT with good short term clinical results in eight patients.

In this technique, the patient rests prone and under general anesthesia. Two medial portals are established through small skin incisions just adjacent to the AT. The proximal portal lies $10 \mathrm{~cm}$ to $12 \mathrm{~cm}$ proximally to the calcaneal tuberosity near the tendon muscle junction, and is used to introduce a $4.5 \mathrm{~mm}$ endoscope pointing to the calcaneus. The distal portal is established just above the calcaneal tuberosity, and is used to introduce a $4.5 \mathrm{~mm}$ full radius motorized shaver pointing the tip of the endoscope and of other surgical instruments. The subcutaneous layers dorsally and ventrally to the AT are split with a mosquito clamp to prepare an adequate space for the endoscope and the shaver. The space located outside the ventral AT is inflated through the endoscope's cannula with normal saline, using an arthroscopic pump. The whole length of the ventral aspect of the tendon is inspected and released completely from the ventral soft tissue using the motorized shaver. Patients with isolated peritendinopathy are managed by simply releasing the tendon from the ventral soft tissue and debridement of the peritendineum. Simultaneous peritendinopathy and tendinopathy of the main body of the tendon are additionally managed with a longitudinal tenotomy through the existing portals. Tenotomy is performed by two parallel longitudinal incisions along the tendon using a retrograde knife blade. The tenotomies are placed according to the magnetic resonance imaging (MRI) images depicting the site of the lesion (medially, ventrally, or dorsally).

\section{Postoperative care}

Postoperatively, patients are allowed to mobilize fully weight bearing. After two weeks, the cast, if used, is removed and 
physiotherapy is commenced, focusing on proprioception, plantar-flexion of the ankle, inversion, and eversion.

\section{Acute AT rupture}

The AT is the most commonly ruptured tendon in the human body. ${ }^{17,34}$ The management of acutely ruptured AT still largely depends on the preference of the surgeon and the patient. Management can be broadly classified into operative (open or percutaneous) and non-operative (cast immobilization or functional bracing). ${ }^{50}$ The management of AT ruptures has changed with time as more evidence is available for the use of early mobilization, ${ }^{51-53}$ and also for the use of percutaneous techniques instead of open surgery. Recent systematic reviews have shown that open operative management of acute AT ruptures significantly reduces the risk of rerupture compared with nonoperative treatment, as it allows accurate apposition of the ruptured tendon ends and earlier motion. However, operative management is associated with a significantly higher risk of wound healing problems. ${ }^{16}$ Operative risks may be reduced by performing surgery percutaneously. ${ }^{50,54}$

The management of AT ruptures aims to minimize the morbidity of the injury, optimize rapid return to full function, and prevent complications. Ismail et $\mathrm{al}^{55}$ recently reported on the Achillon mini-incision technique, comparing the basic mechanical properties of the tendon suture performed using the Achillon method with those of the long established Kessler method, and assesses whether the strength of the repair was related to tendon diameter. The Achillon repair had comparable tensile strength to the Kessler repair.

We use Carmont and Maffulli's technique, ${ }^{18}$ the procedure is cheap, and allows a strong repair, as it enables us to use a greater number of suture strands (eight) for the repair of the AT. Biomechanical studies are ongoing, and preliminary results seem to confirm this. This technique provided favorable outcome for patients older than 65 , producing similar outcomes when compared to percutaneous repair in younger patients of previous reports. ${ }^{11}$

\section{Percutaneous repair of acute AT rupture}

The patient is positioned prone. Areas $4-6 \mathrm{~cm}$ proximal and distal to the palpable tendon defect and the skin over the defect are infiltrated with $20 \mathrm{ml}$ of $1 \%$ lignocaine. Ten $\mathrm{ml}$ of Chirocaine ${ }^{\circledR} 0.5 \%$ is infiltrated deep to the tendon defect. A calf tourniquet, skin preparation and steridrapes are applied.

A $1 \mathrm{~cm}$ transverse incision is made over the defect using a size 11 blade (Swann-Morton Ltd). Four longitudinal stab incisions are made lateral and medial to the tendon $6 \mathrm{~cm}$ proximal to the palpable defect. Two further longitudinal incisions on either side of the tendon are made 4-6 cm distal to the palpable defect. Forceps are then used to mobilize the tendon from beneath the subcutaneous tissues. A $9 \mathrm{~cm}$ Mayo needle (BL059N, \#B00 round point spring eye, B Braun, Aesculap, Tuttlingen, Germany) is threaded with two double loops of Number 1 Maxon (Tyco Healthcare, Norwalk, CT, USA), and this is passed transversely between the proximal stab incisions through the bulk of the tendon. The bulk of the tendon is surprisingly superficial. The loose ends are held with a clip. In turn, each of the ends is then passed distally from just proximal to the transverse Maxon passage through the bulk of the tendon to pass out of the diagonally opposing stab incision. A subsequent diagonal pass is then made to the transverse incision over the ruptured tendon. To prevent entanglement, both ends of the Maxon are held in separate clips. This suture is then tested for security by pulling with both ends of the Maxon distally. Another double loop of Maxon is then passed between the distal stab incisions through the tendon, and in turn through the tendon and out of the transverse incision starting distal to the transverse passage. The ankle is held in full plantar flexion, and in turn opposing ends of the Maxon thread are tied together with a double throw knot, and then three further throws before being buried using the forceps. A clip is used to hold the first throw of the lateral side to maintain the tension of the suture.

A subcuticular Biosyn suture 3.0 (Tyco Healthcare) is used to close the transverse incision, and Steri-strips (3M Health Care, St Paul, MN, USA) are applied to the stab incisions. Finally, a Mepore dressing (Molnlycke Health Care) is applied, and a bivalved removable scotch cast in full plantar flexion is applied being held in place with Velcro straps.

The patient is allowed home on the day of surgery, and fully weight bears as able in the cast in full plantar flexion. At two weeks, the wounds are inspected, and the back shell is removed allowing proprioception, plantar flexion, inversion, and eversion exercises. The front shell remains in place for six weeks to prevent forced dorsiflexion of the ankle.

\section{Chronic AT ruptures}

The management of chronic ruptures of tendo Achillis is usually different from that of acute rupture, as the tendon ends normally will have retracted. ${ }^{17,56,57}$ The blood supply to this area is relatively poor, and the tendon ends have to be freshened to allow healing. Due to the increased gap, primary repair is not generally possible. ${ }^{57}$ Operative procedures for reconstruction of the AT include flap tissue turn 
down using one ${ }^{58,59}$ and two flaps, ${ }^{60}$ local tendon transfer, ${ }^{61-64}$ and autologous hamstring tendon harvesting. ${ }^{65}$ All of these techniques use a single longitudinal incision for exposure. Following these procedures, complications, especially wound breakdown and infection (9\%), ${ }^{66}$ are not infrequent, and are probably related to the paucity of the soft tissue vascularity, and may require plastic surgical procedures to cover significant soft tissue defects. ${ }^{67}$

We have described a less invasive technique of peroneus brevis reconstruction for the AT using two para-midline incisions. ${ }^{17}$ This technique allows reconstruction of the AT using peroneus brevis preserving skin integrity over the site most prone to wound breakdown. Sometimes during surgery, after trying to reduce the gap of the ruptured AT, the gap produced is greater than $6 \mathrm{~cm}$ despite maximal plantar flexion of the ankle and traction on the AT stumps. ${ }^{17}$ In such instances, peroneus brevis is not sufficient to fill the gap, and ipsilateral hamstring tendon harvesting can be an option. ${ }^{64}$

\section{Peroneus brevis transfer}

The patient is positioned prone with a calf tourniquet. Skin preparation is performed in the usual fashion, and sterile drapes are applied. Preoperative anatomical markings include the palpable tendon defect, both malleoli, and the base of the fifth metatarsal.

Three skin incisions are made, and accurate hemostasis by ligation of the larger veins and diathermy of the smaller ones is performed. ${ }^{17}$ The first incision is a $5 \mathrm{~cm}$ longitudinal incision, made $2 \mathrm{~cm}$ proximal and just medial to the palpable end of the residual tendon. The second incision is $3 \mathrm{~cm}$ long and is also longitudinal, but is $2 \mathrm{~cm}$ distal and lateral to the distal end of the tendon rupture. Care is taken to prevent damage to the sural nerve by making this incision as close as possible to the anterior aspect of the lateral border of the AT to avoid the nerve. At the level of the AT insertion, the sural nerve is $18.8 \mathrm{~mm}$ lateral to the tendon, but as it progresses proximally the nerve gradually traverses medially crossing the lateral border of the tendon $9.8 \mathrm{~cm}$ proximal to the calcaneum. Thus, the second incision avoids the sural nerve by being placed on the lateral side of the AT, but medial to the nerve. The third incision is a $2 \mathrm{~cm}$ longitudinal incision at the base of the fifth metatarsal.

The distal AT stump is mobilized, freeing it of all the peritendinous adhesions, particularly on the lateral aspect. This allows access to the base of the lateral aspect of the distal tendon close to its insertion. It should be possible to palpate the medial tubercle of the calcaneum. The ruptured tendon end is then resected back to healthy tendon, and a No. 1
Vicryl (Ethicon, Edinburgh) locking suture is run along the free tendon edge to prevent separation of the bundles.

The proximal tendon is then mobilized from the proximal wound, any adhesions are divided, and further soft tissue release anterior to the soleus and gastrocnemius allows maximal excursion, minimizing the gap between the two tendon stumps. A Vicryl locking suture is run along the free tendon edge to allow adequate exposure and to prevent separation of the bundles.

The tendon of peroneus brevis is harvested. The tendon is identified through the incision on the lateral border of the foot at its insertion at the base of the fifth metatarsal. The tendon is exposed, and a No.1 Vicryl locking suture is applied to the tendon end before release from the metatarsal base. The tendon of peroneus brevis is identified at the base of the distal incision of the AT following incision of the deep fascia overlying the peroneal muscles compartment. The tendon of peroneus brevis is then withdrawn through the distal wound. This may take significant force, as there may be tendinous strands between the two peroneal tendons distally. The muscular portion of peroneus brevis is then mobilized proximally to allow increased excursion of the tendon of peroneus brevis.

A longitudinal tenotomy parallel to the tendon fibers is made through both stumps of the tendon. A clip is used to develop the plane, from lateral to medial, in the distal stump of the AT and the peroneus brevis graft is passed through the tenotomy. With the ankle in maximal plantar flexion, a No.1 Vicryl suture is used to suture the peroneus brevis to both sides of the distal stump. The tendon of peroneus brevis is then passed beneath the intact skin bridge into the proximal incision, and passed from medial to lateral through a transverse tenotomy in the proximal stump, and further secured with No. 1 Vicryl. Finally, the tendon of peroneus brevis is sutured back onto itself on the lateral side of the proximal incision. The reconstruction may be further augmented using a Maxon (Tyco Health Care) suture.

The wounds are closed with 2.0 Vicryl, 3.0 Biosyn (Tyco Health Care) and Steri-strips (3M Health Care, MN), taking care to avoid the risk of post operative hematoma and minimize wound breakdown. A previously prepared removable scotch cast support with Velcro straps is applied.

Postoperatively, patients are allowed to weight bear as comfort allows with the use of elbow crutches. It would be unusual for a patient to weight bear fully at this stage. After two weeks, the back shell is removed, and physiotherapy is commenced with the front shell in situ preventing dorsiflexion of the ankle, focusing on proprioception, plantar-flexion 
of the ankle, inversion and, eversion. During this period of rehabilitation the patient is permitted to weight bear as comfort allows with the front shell in situ, although full weight bearing rarely occurs on account of balance difficulties. Patients usually still require the assistance of a single elbow crutch as this stage. The front shell may be finally removed after six weeks. We do not use a heel raise after removal of the cast, and patients normally regain a plantigrade ankle over a couple of weeks.

\section{Ipsilateral free semitendinosus tendon graft transfer for chronic tears of the AT}

The patient is positioned prone with a calf tourniquet. ${ }^{8}$ Skin preparation is performed in the usual fashion, and sterile drapes are applied. Preoperative anatomical markings include the palpable tendon defect and both malleoli. ${ }^{8}$ Two skin incisions are made, and accurate hemostasis by ligation of the larger veins and diathermy of the smaller ones is performed. The first incision is a $5 \mathrm{~cm}$ longitudinal incision, made $2 \mathrm{~cm}$ proximal and just medial to the palpable end of the residual tendon. The second incision is $3 \mathrm{~cm}$ long and is also longitudinal, but is $2 \mathrm{~cm}$ distal and in the midline over the distal end of the tendon rupture. Care is taken to prevent damage to the sural nerve. At the level of the AT insertion, the sural nerve is $18.8 \mathrm{~mm}$ lateral to the tendon, but as it progresses proximally, the nerve gradually traverses medially crossing the lateral border of the tendon $9.8 \mathrm{~cm}$ proximal to the calcaneum. ${ }^{68}$ Thus, the second incision avoids the sural nerve by being placed medial to the nerve.

The proximal and distal AT stump are mobilized, freeing them of all the peritendinous adhesions. It should be possible to palpate the medial tubercle of the calcaneum. The ruptured tendon end is then resected back to healthy tendon, and a No. 1 Vicryl (Ethicon, Edinburgh) locking suture is run along the free tendon edge to prevent separation of the bundles.

The proximal tendon is then mobilized from the proximal wound, any adhesions are divided, and further soft tissue release anterior to the soleus and gastrocnemius allows maximal excursion, minimizing the gap between the two tendon stumps. A Vicryl locking suture is run along the free tendon edge to allow adequate exposure and to prevent separation of the bundles.

After trying to reduce the gap of the ruptured AT, if the gap produced is greater than $6 \mathrm{~cm}$ despite maximal plantar flexion of the ankle and traction on the AT stumps, the ipsilateral semitendinosus is harvested.
The tendon of the semitendinosus is harvested through a vertical $2.5-3 \mathrm{~cm}$ longitudinal incision over the pes anserinus. The semitendinosus tendon is passed through a small incision in the substance of the proximal stump of the AT, and it is sutured to the AT at the entry and exit point using 3-0 Vicryl (Polyglactin 910 braided absorbable suture; Johnson and Johnson, Brussels, Belgium). The semitendinosus tendon is then passed beneath the intact skin bridge into the distal incision, and passed from medial to lateral through a transverse tenotomy in the distal stump. With the ankle in maximal plantar flexion, the semitendinosus tendon is sutured to the AT at each entry and exit point using 3-0 Vicryl (Polyglactin 910 braided absorbable suture; Johnson and Johnson). The repair is tensioned to maximal equines.

One extremity of the semitendinosus tendon is then passed again beneath the intact skin bridge into the proximal incision, and passed from medial to lateral through a transverse tenotomy in the proximal stump. The other extremity of the semitendinosus tendon is then passed again from medial to lateral through a transverse tenotomy in the distal stump. The reconstruction may be further augmented using a Maxon (Tyco Health Care) suture. The wounds are closed with 2.0 Vicryl, 3,0 Biosyn (Tyco Health Care) and Steri-strips (3M Health Care, MN). A previously prepared removable scotch cast support with Velcro straps is applied.

Postoperatively, patients are allowed to weight bear as comfort allows with the use of elbow crutches. ${ }^{51,52}$ It would be unusual for a patient to weight bear fully at this stage. After two weeks, the back shell is removed and physiotherapy is commenced with the front shell in situ preventing dorsiflexion of the ankle, focusing on proprioception, plantar-flexion of the ankle, inversion, and eversion. ${ }^{51,52}$ During this period of rehabilitation, the patient is permitted to weight bear as comfort allows with the front shell in situ although full weight bearing rarely occurs on account of balance difficulties and patients usually still require the assistance of a single elbow crutch as this stage. The front shell may be finally removed after six weeks. We do not use a heel raise after removal of the cast, and patients normally regain a plantigrade ankle over two or three weeks. ${ }^{51,52}$

\section{Free hamstrings tendon transfer and interference screw fixation for less invasive reconstruction of chronic avulsions of the AT}

Chronic avulsions of the AT from the calcaneus are infrequent. ${ }^{34,38,56,69}$ Open reduction and fixation is possible only when a large bony fragment is avulsed. In patients with 
Achilles "sleeve" avulsions, the tendon sleeves from its insertion into the calcaneus leaving virtually no tendinous tissue on the posterior calcaneus to facilitate a repair to the free end of the $\mathrm{AT}^{70}$ We described a method of less invasive semitendinosus reconstruction for chronic avulsion of the AT. ${ }^{12}$ This technique uses one proximal para-midline incision and one distal Cincinnati incision to respectively expose the proximal AT stump and the AT insertion. Using this approach, a wide exposure of the insertion of the AT is possible. The patient is positioned prone with a calf tourniquet. Skin preparation is performed in the usual fashion, and sterile drapes are applied. Preoperative anatomical markings include the palpable tendon defect and the tuberosity of the calcaneus. Two skin incisions are made, and accurate hemostasis by ligation of the larger veins and diathermy of the smaller ones is performed. The first incision is a $5 \mathrm{~cm}$ longitudinal incision, made $2 \mathrm{~cm}$ proximal and just medial to the palpable end of the residual tendon. The second incision is 5 to $7 \mathrm{~cm}$ semicircular Cincinnati skin incision, ${ }^{71}$ made over the area of AT insertion.

The proximal and distal AT stumps are mobilized, freeing them of all the peritendinous adhesions. After trying to reduce the gap of the ruptured AT, if the gap does not allow the tendon to reach the bone despite maximal plantar flexion of the ankle and traction on the AT stump, the ipsilateral semitendinosus is harvested through a vertical $2.5-3 \mathrm{~cm}$ long incision over the pes anserinus. The tendon is prepared in the usual fashion. ${ }^{15}$

A cannulated headed reamer corresponding to the grafts diameter is used to perforate the calcaneus to allow the passage of the double-looped semitendinosus tendon graft. A wire is then passed through the tunnel.

The proximal tendon is then mobilized from the proximal wound, any adhesions are divided, and further soft tissue release anterior to the soleus and gastrocnemius allows maximal excursion, minimizing the gap between the two tendon stumps. The semitendinosus tendon is passed through a small incision in the substance of the proximal stump of the AT, and it is sutured to the AT at the entry and exit point using 3-0 Vicryl (Polyglactin 910 braided absorbable suture; Johnson and Johnson). The semitendinosus tendon is then passed beneath the intact skin bridge into the distal incision, and then through the calcaneus tunnel. With the ankle in maximal plantar flexion, the semitendinosus tendon is fixed to the calcaneus using a bioabsorbable interference screw inserted over a guide wire into the calcaneus.

The patient is immobilized in a below-knee weight-bearing synthetic cast boot. Postoperatively, patients are allowed to weight bear as comfort allows with the use of elbow crutches. ${ }^{51,52}$ It would be unusual for a patient to weight bear fully at this stage. After two weeks, the cast is removed and an Aircast boot with five heel wedges (XP Walker, DJO Ltd, Guilford, England) is applied and physiotherapy is commenced preventing dorsiflexion of the ankle, focusing on proprioception, plantar-flexion of the ankle, inversion, and eversion. ${ }^{51,52}$ During this period of rehabilitation, the patient is permitted to weight bear as comfort allows with the boot in situ, although full weight bearing rarely occurs and patients usually still require the assistance of a single elbow crutch as this stage. One heel wedge is removed every other week, and the boot may be finally removed after six weeks. We do not use a heel raise after removal of the boot, and patients normally regain a plantigrade ankle over two or three weeks. ${ }^{51,52}$

\section{Conclusion}

The nascent literature on minimally invasive AT surgery is far from universally supportive. Most series that have been published in support of these surgical approaches are first reports by originators of particular techniques. Randomized controlled trials are required to address the issue of the comparison between open versus minimally invasive AT surgery. In our hands, minimally invasive surgery has provided similar results to those obtained with open surgery, providing decreased perioperative morbidity, decreased duration of hospital stay, and reduced costs. Multicenter studies with longer follow-up are needed to justify the long-term advantages of these techniques over traditional ones.

\section{Disclosure}

The authors report no conflicts of interest in this work.

\section{References}

1. Ho M, Garau G, Walley G, et al. Minimally invasive dynamic hip screw for fixation of hip fractures. Int Orthop. 2009;33(2):555-560.

2. Khanna A, Gougoulias N, Longo UG, Maffulli N. Minimally invasive total knee arthroplasty: a systematic review. Orthop Clin North Am. 2009;40(4):479-489.

3. Longo UG, Maffulli N, Denaro V. Minimally invasive total knee arthroplasty. N Engl J Med. 2009;361(6):633-634.

4. Longo UG, Papapietro N, Maffulli N, Denaro V. Thoracoscopy for minimally invasive thoracic spine surgery. Orthop Clin North Am. 2009;40(4):459-464

5. Longo UG, Ramamurthy C, Denaro V, Maffulli N. Minimally invasive stripping for chronic Achilles tendinopathy. Disabil Rehabil. 2008; 30(20-22):1709-1713.

6. Maffulli N, Longo UG, Denaro V. Letter to the editor: minimally invasive paratenon release for non-insertional Achilles tendinopathy. Foot Ankle Int. 2009;30(10):1027-1028. 
7. Maffulli N, Longo UG, Denaro V. Complications after surgery or nonoperative treatment for acute Achilles tendon rupture. Clin J Sport Med. 2009;19(5):441-442.

8. Maffulli N, Longo UG, Gougoulias N, Denaro V. Ipsilateral free semitendinosus tendon graft transfer for reconstruction of chronic tears of the Achilles tendon. BMC Musculoskelet Disord. 2008;9:100.

9. Maffulli N, Longo UG, Oliva F, Denaro V, Coppola C. Bosch osteotomy and scarf osteotomy for hallux valgus correction. Orthop Clin North Am. 2009;40(4):515-524.

10. Maffulli N, Longo UG, Oliva F, Ronga M, Denaro V. Minimally invasive surgery of the Achilles tendon. Orthop Clin North Am. 2009;40(4): 491-498.

11. Maffulli N, Longo UG, Ronga M, Khanna A, Denaro V. Favorable outcome of percutaneous repair of Achilles tendon ruptures in the elderly. Clin Orthop Relat Res. 2010;468(4):1039-1046.

12. Maffulli N, Longo UG, Spiezia F, Denaro V. Free hamstrings tendon transfer and interference screw fixation for less invasive reconstruction of chronic avulsions of the Achilles tendon. Knee Surg Sports Traumatol Arthrosc. 2010;18(2):269-273.

13. Oliva F, Longo UG, Maffulli N. Minimally invasive hallux valgus correction. Orthop Clin North Am. 2009;40(4):525-530.

14. Ronga M, Longo UG, Maffulli N. Minimally invasive locked plating of distal tibia fractures is safe and effective. Clin Orthop Relat Res. 2010;468(4):975-982.

15. Ronga M, Shanmugam C, Longo UG, Oliva F, Maffulli N. Minimally invasive osteosynthesis of distal tibial fractures using locking plates. Orthop Clin North Am. 2009;40(4):499-504.

16. Saxena A, Maffulli N, Nguyen A, Li A. Wound complications from surgeries pertaining to the Achilles tendon: an analysis of 219 surgeries. J Am Podiatr Med Assoc. 2008;98(2):95-101.

17. Carmont MR, Maffulli N. Less invasive Achilles tendon reconstruction. BMC Musculoskelet Disord. 2007;8:100.

18. Carmont MR, Maffulli N. Modified percutaneous repair of ruptured Achilles tendon. Knee Surg Sports Traumatol Arthrosc. 2008;16(2): 199-203.

19. Maffulli N, Testa V, Capasso G, Bifulco G, Binfield PM. Results of percutaneous longitudinal tenotomy for Achilles tendinopathy in middleand long-distance runners. Am J Sports Med. 1997;25(6):835-840.

20. Testa V, Capasso G, Benazzo F, Maffulli N. Management of Achilles tendinopathy by ultrasound-guided percutaneous tenotomy. Med Sci Sports Exerc. 2002;34(4):573-580.

21. Longo UG, Ronga M, Maffulli N. Acute ruptures of the Achilles tendon. Sports Med Arthrosc. 2009;17(2):127-138.

22. Longo UG, Ronga M, Maffulli N. Achilles tendinopathy. Sports Med Arthrosc. 2009;17(2):112-126.

23. Longo UG, Oliva F, Denaro V, Maffulli N. Oxygen species and overuse tendinopathy in athletes. Disabil Rehabil. 2008;30(20-22):1563-1571.

24. Alfredson H, Ohberg L, Forsgren S. Is vasculo-neural ingrowth the cause of pain in chronic Achilles tendinosis? An investigation using ultrasonography and colour Doppler, immunohistochemistry, and diagnostic injections. Knee Surg Sports Traumatol Arthrosc. 2003;11(5):334-338.

25. Knobloch K, Kraemer R, Lichtenberg A, et al. Achilles tendon and paratendon microcirculation in midportion and insertional tendinopathy in athletes. Am J Sports Med. 2006;34(1):92-97.

26. Kristoffersen M, Ohberg L, Johnston C, Alfredson H. Neovascularisation in chronic tendon injuries detected with colour Doppler ultrasound in horse and man: implications for research and treatment. Knee Surg Sports Traumatol Arthrosc. 2005;13(6):505-508.

27. Ohberg L, Lorentzon R, Alfredson H. Neovascularisation in Achilles tendons with painful tendinosis but not in normal tendons: an ultrasonographic investigation. Knee Surg Sports Traumatol Arthrosc. 2001;9(4): 233-238.

28. Maffulli N, Sharma P, Luscombe KL. Achilles tendinopathy: aetiology and management. $J$ R Soc Med. 2004;97(10):472-476.

29. Maffulli N, Testa V, Capasso G, et al. Similar histopathological picture in males with Achilles and patellar tendinopathy. Med Sci Sports Exerc. 2004;36(9):1470-1475.
30. Maffulli N, Wong J, Almekinders LC. Types and epidemiology of tendinopathy. Clin Sports Med. 2003;22(4):675-692.

31. Denaro V, Ruzzini L, Longo UG, et al. Effect of dihydrotestosterone on cultured human tenocytes from intact supraspinatus tendon. Knee Surg Sports Traumatol Arthrosc. 2009; Oct 27. [Epub ahead of print].

32. Longo UG, Rittweger J, Garau G, et al. No influence of age, gender, weight, height, and impact profile in achilles tendinopathy in masters track and field athletes. Am J Sports Med. 2009;37(7):1400-1405.

33. Maffulli N, Longo UG, Franceschi F, Rabitti C, Denaro V. Movin and Bonar scores assess the same characteristics of tendon histology. Clin Orthop Relat Res. 2008;466(7):1605-1611.

34. Ames PR, Longo UG, Denaro V, Maffulli N. Achilles tendon problems: not just an orthopedic issue. Disabil Rehabil. 2008;30(20-22): $1646-1650$.

35. Maffulli N, Longo UG. How do eccentric exercises work in tendinopathy? Rheumatology (Oxford). 2008;47(10):1444-1445.

36. Maffulli N, Longo UG. Conservative management for tendinopathy: is there enough scientific evidence? Rheumatology (Oxford). 2008;47(4):390-391.

37. Maffulli N, Walley G, Sayana MK, Longo UG, Denaro V. Eccentric calf muscle training in athletic patients with Achilles tendinopathy. Disabil Rehabil. 2008;30(20-22):1677-1684.

38. Maffulli N, Testa V, Capasso G, et al. Surgery for chronic Achilles tendinopathy produces worse results in women. Disabil Rehabil. 2008;30(20-22):1714-1720.

39. Rolf C, Movin T. Etiology, histopathology, and outcome of surgery in achillodynia. Foot Ankle Int. 1997;18(9):565-569.

40. Thermann H, Benetos IS, Panelli C, Gavriilidis I, Feil S. Endoscopic treatment of chronic mid-portion Achilles tendinopathy: novel technique with short-term results. Knee Surg Sports Traumatol Arthrosc. 2009;17(10):1264-1269.

41. Steenstra F, van Dijk CN. Achilles tendoscopy. Foot Ankle Clin. 2006;11(2):429-438.

42. Maffulli N, Pintore E, Petricciuolo F. Arthroscopy wounds: to suture or not to suture. Acta Orthop Belg. 1991;57(2):154-156.

43. Maffulli N, Dymond NP, Regine R. Surgical repair of ruptured Achilles tendon in sportsmen and sedentary patients: a longitudinal ultrasound assessment. Int J Sports Med. 1990;11(1):78-84.

44. Sayana MK, Maffulli N. Eccentric calf muscle training in nonathletic patients with Achilles tendinopathy. J Sci Med Sport. 2007;10(1):52-58.

45. van Dijk CN, Kort N, Scholten PE. Tendoscopy of the posterior tibial tendon. Arthroscopy. 1997;13(6):692-698.

46. Scholten PE, van Dijk CN. Tendoscopy of the peroneal tendons. Foot Ankle Clin. 2006;11(2):415-420.

47. van Dijk CN, Kort N. Tendoscopy of the peroneal tendons. Arthroscopy. 1998;14(5):471-478.

48. Scholten PE, van Dijk CN. Endoscopic calcaneoplasty. Foot Ankle Clin. 2006;11(2):439-446.

49. van Dijk CN, van Dyk GE, Scholten PE, Kort NP. Endoscopic calcaneoplasty. Am J Sports Med. 2001;29(2):185-189.

50. Ebinesan AD, Sarai BS, Walley GD, Maffulli N. Conservative, open, or percutaneous repair for acute rupture of the Achilles tendon. Disabil Rehabil. 2008;30(20-22):1721-1725.

51. Maffulli N, Tallon C, Wong J, Lim KP, Bleakney R. Early weightbearing and ankle mobilization after open repair of acute midsubstance tears of the Achilles tendon. Am J Sports Med. 2003;31(5):692-700.

52. Maffulli N, Tallon C, Wong J, Peng Lim K, Bleakney R. No adverse effect of early weight bearing following open repair of acute tears of the Achilles tendon. J Sports Med Phys Fitness. 2003;43(3): 367-379.

53. Maffulli N. Immediate weight-bearing is not detrimental to operatively or conservatively managed rupture of the Achilles tendon. Aust J Physiother. 2006;52(3):225.

54. Khan RJ, Fick D, Keogh A, Crawford J, Brammar T, Parker M. Treatment of acute Achilles tendon ruptures. A meta-analysis of randomized, controlled trials. J Bone Joint Surg Am. 2005;87(10):2202-2210. 
55. Ismail M, Karim A, Shulman R, Amis A, Calder J. The Achillon Achilles tendon repair: is it strong enough? Foot Ankle Int. 2008;29(8): 808-813.

56. Maffulli N, Ajis A, Longo UG, Denaro V. Chronic rupture of tendo Achillis. Foot Ankle Clin. 2007;12(4):583-596.

57. Maffulli N. Rupture of the Achilles tendon. J Bone Joint Surg Am. 1999;81(7):1019-1036.

58. Lee YS, Lin CC, Chen CN, Chen SH, Liao WY, Huang CR. Reconstruction for neglected Achilles tendon rupture: the modified Bosworth technique. Orthopedics. 2005;28(7):647-650.

59. Christensen I. Rupture of the Achilles tendon: analysis of 57 cases. Acta Chir Scand. 1953;106(1):50-60.

60. Arner O, Lindholm A. Subcutaneous rupture of the Achilles tendon: a study of 92 cases. Acta Chir Scand Suppl. 1959;116 Suppl 239:1-51.

61. Dekker M, Bender J. Results of surgical treatment of rupture of the Achilles tendon with use of the plantaris tendon. Arch Chir Neerl. 1977; 29(1):39-46.

62. Wapner KL, Pavlock GS, Hecht PJ, Naselli F, Walther R. Repair of chronic Achilles tendon rupture with flexor hallucis longus tendon transfer. Foot Ankle. 1993;14(8):443-449.

63. Wilcox DK, Bohay DR, Anderson JG. Treatment of chronic Achilles tendon disorders with flexor hallucis longus tendon transfer/augmentation. Foot Ankle Int. 2000;21(12):1004-1010.
64. McClelland D, Maffulli N. Neglected rupture of the Achilles tendon: reconstruction with peroneus brevis tendon transfer. Surgeon. 2004; 2(4):209-213.

65. Maffulli N, Leadbetter WB. Free gracilis tendon graft in neglected tears of the Achilles tendon. Clin J Sport Med. 2005;15(2):56-61.

66. Pintore E, Barra V, Pintore R, Maffulli N. Peroneus brevis tendon transfer in neglected tears of the Achilles tendon. JTrauma. 2001;50(1): 71-78.

67. Kumta SM, Maffulli N. Local flap coverage for soft tissue defects following open repair of Achilles tendon rupture. Acta Orthop Belg. 2003;69(1):59-66.

68. Webb J, Moorjani N, Radford M. Anatomy of the sural nerve and its relation to the Achilles tendon. Foot Ankle Int. 2000;21(6):475-477.

69. Silbernagel KG, Nilsson-Helander K, Thomee R, Eriksson BI, Karlsson J. A new measurement of heel-rise endurance with the ability to detect functional deficits in patients with Achilles tendon rupture. Knee Surg Sports Traumatol Arthrosc. 2010;18(2):258-64.

70. Pavlou G, Roach R, Salehi-Bird S. Repair of the achilles tendon sleeve avulsion: a transcalcaneal suture technique. Foot Ankle Int. 2009;30(1): 65-67.

71. Carmont MR, Maffulli N. Management of insertional Achilles tendinopathy through a Cincinnati incision. BMC Musculoskelet Disord. 2007;8:82.
Open Access Journal of Sports Medicine

\section{Publish your work in this journal}

Open Access Journal of Sports Medicine is an international, peer-reviewed, open access journal publishing original research, reports, reviews and commentaries on all areas of sports medicine. The manuscript management system is completely online and includes a very quick and fair peer-review system.

\section{Dovepress}

Visit http://www.dovepress.com/testimonials.php to read real quotes from published authors. 